\title{
Dilated azygos arch mimicking an aortic arch anomaly during thoracic surgery
}

\author{
Ingrid Anne Mandy Schierz, Ettore Piro, Mario Giuffrè, Giuseppa Pinello, Giovanni Corsello \\ Neonatal Intensive Care Unit, AOUP “P. Giaccone”, Department of Sciences for Health Promotion and Mother and Child Care "G. D'Alessandro", University of Palermo,
} Via Alfonso Giordano n. 3, 90127 Palermo, Italy

\section{A R T I C L E I N F O}

\section{Keywords:}

Azygos continuation

Cardiovascular abnormalities

Tracheoesophageal fistula

\begin{abstract}
A B S T R A C T
Cardiovascular malformations are frequently associated in patients with esophageal atresia (EA). We observed azygos continuation mimicking an aortic arch anomaly in four newborns with type III EA. They presented concomitant rib anomalies indicating a common developmental defect. Foreknowledge is important for planning thoracotomy or interventional cardiac catheterization in this population.
\end{abstract}

\section{Background}

Cardiovascular malformations are the most frequent associated anomalies in patients with esophageal atresia (EA) as part of a complex spectrum of axial mesodermal dysplasia [11,15]. Several studies are reporting caudal pharyngeal arch neurocristopathies like aortic arch anomalies, carotid anomalies, aberrant retroesophageal right subclavian artery, conotruncal heart defects or persistent left superior vena cava (SVC) $[1,11,15,23]$. Therefore, during the preoperative echocardiographic evaluation, sonographers should pay attention to establish the laterality of aortic arch and its anomalies. Otherwise, also some venous anomalies should be ruled out for various motivations. First one, azygos vein (AV) anomalies are reported to be associated with a wider gap between the esophageal pouches, with higher morbidity and mortality [9]. Second, an absent AV makes more difficult during intervention the identification of the distal tracheoesophageal fistula $[1,21]$. And third, a dilated azygos arch, as an expression of systemic circulatory alteration, can mimic a right aortic arch during intervention inducing the surgeon to an erroneous approach. We report the clinical features of these rare systemic venous anomalies with emphasis on the practical implications of the diagnosis and the importance of preoperative assessment of patients with EA.

\section{Methods}

A retrospective chart review was performed on all newborns admitted to the neonatal intensive care unit for type III EA between January 1, 2013 and October 31, 2016. Data from routinely preopera- tive X-ray, ECG, echocardiogram, abdominal ultrasound (US), operation report, clinical course, and genetical testing were collected. Univariate analyses were performed by open source statistical $\mathrm{R}$ Commander "Palermo software package" [17] using the Fisher's exact test for categorical variables and the two-sample $t$-test for continuous variables; $p<0.05$ was considered significant.

\section{Results}

Over this four-year period, dilated AV due to azygos continuation of the inferior vena cava (IVC) in situs solitus was evidenced by colorDoppler US in 4/20 (20\%) newborns with type III EA. The dilated AV was lying behind the right renal artery and intra-thoracically was entering the superior surface of the right atrium or SVC as a dilated right bluish arch. This evidence was confirmed during thoracotomy and the surgeon did not perform the AV division, as it is frequently practiced [21] during the tracheoesophageal fistula repair and esophageal anastomosis. We did not find AV agenesis or duplication, venous thrombosis, associated malrotation (demonstrating normal position of superior mesenteric vein and artery by US and/or normal cecal position by enemas) or other signs of isomerism (normal atria, liver, spleen, stomach, pancreas, and biliary tree by US).

The four outborn infants with azygos continuation were born at term without prenatal diagnosis of EA, despite the evidence of polyhydramnios. They presented rib number anomalies $(p=0.003)$ and other associated malformations as listed in Table 1. Particularly, an associated azygos accessory lobe was evidenced on thoracic CT in patient 1 . There was no significant difference in means or frequencies between

\footnotetext{
Abbreviations: AV, azygos vein; EA, esophageal atresia; IVC, inferior vena cava; SVC, superior vena cava; US, ultrasound

* Corresponding author.

E-mail addresses: inschier@tin.it (I.A.M. Schierz), ettore.piro@unipa.it (E. Piro), mario.giuffre@unipa.it (M. Giuffrè), giusypinello@gmail.com (G. Pinello), giocors@aliceposta.it (G. Corsello).
} 
Table 1

Mean values and frequencies observed in newborns with and without azygos continuation in the type III esophageal atresia (EA/III) population.

\begin{tabular}{|c|c|c|c|c|c|c|}
\hline EA/III & $\begin{array}{l}\text { Birth weight, } g \\
\text { (range) }\end{array}$ & $\begin{array}{l}\text { Rib number } \\
\text { anomaly, \% (rib } \\
\text { pairs) }\end{array}$ & $\begin{array}{l}\text { Congenital heart } \\
\text { diseases, \% }\end{array}$ & $\begin{array}{l}\text { Other non-cardio-vascular } \\
\text { anomalies, \% }\end{array}$ & $\begin{array}{l}\text { Related } \\
\text { syndrome, \% }\end{array}$ & $\begin{array}{l}\text { Discharged home, } \\
\text { days }\end{array}$ \\
\hline $\begin{array}{l}\text { Azygos continuation } \\
\qquad(n=4)\end{array}$ & $\begin{array}{l}2886 \\
(2040-3955)\end{array}$ & 100 & 50 & 75 & 50 & 39 \\
\hline Pat. 1 & 2300 & (11) & LSVC, PDA & $\begin{array}{l}\text { Hemisoma, SUA, anemia, azygos } \\
\text { lobe, postsurgical chylothorax }\end{array}$ & & 64 \\
\hline Pat. 2 & 3955 & (11) & & Macrosomia, laterocervical tumor & Down & 23 \\
\hline Pat. 3 & 2040 & (13) & Subaortic VSD & IUGR, anemia, hypothyroidism, & & 25 \\
\hline Pat. 4 & 3250 & (13) & HOCM & $\begin{array}{l}\text { ARM, absent coccyx, anemia, } \\
\text { hydronephrosis }\end{array}$ & VACTERL & 44 \\
\hline $\begin{array}{l}\text { Non-azygos continuation } \\
\quad(n=16)\end{array}$ & $\begin{array}{l}2283 \\
(580-3625)\end{array}$ & 12.5 & 50 & 56 & 56 & 33 \\
\hline$p$-Value & 0.28 & 0.003 & 1 & 0.49 & 0.82 & 0.63 \\
\hline Prevalence ratio $(95 \% \mathrm{CI})$ & & $\begin{array}{l}8 \\
(2.19,29.25)\end{array}$ & $\begin{array}{l}1 \\
(0.33,2.99)\end{array}$ & $\begin{array}{l}1.42 \\
(0.65,2.72)\end{array}$ & $\begin{array}{l}0.89 \\
(0.30,2.59)\end{array}$ & \\
\hline
\end{tabular}

Abbreviations: ARM, anorectal malformation; HOCM, hypertrophic cardiomyopathy; IUGR, intrauterine growth restriction; LSVC, persistent left superior vena cava; PDA, persistent ductus arteriosus; SUA, single umbilical artery; VSD, ventricular septum defect.

newborns with and without azygos continuation with regard to maternal age (33.5 vs 36 years), gestational age (38 vs 36 weeks), birth weight percentile $\left(31^{\circ}\right.$ vs $\left.26^{\circ}\right)$, gender ( 75 vs $44 \%$ female), twinning ( 0 vs $12.5 \%$ ), omphalocele (0 vs $6 \%$ ), left SVC ( 25 vs $0 \%$ ), single umbilical artery ( 25 vs $0 \%$ ), kidney disorders ( 25 vs $19 \%$ ), related syndromes (50 vs $56 \%$ ), gap-distance (1.7 vs $1.7 \mathrm{~cm})$, time to achieve full enteral nutrition ( 26 vs 19 days), surgical complications ( 25 vs $6 \%$ ), infections ( 0 vs $25 \%$ ) or mortality ( 0 vs $18.7 \%$ ).

\section{Discussion}

In all patients, the sonographic evidence of azygos continuation was confirmed during thoracotomy. This asymptomatic developmental variation, secondary to interruption of at least the hepatic segment of the IVC, should be considered part of the clinical spectrum of the polymalformative complex EA with rib disorders. Although other AV anomalies have been reported in patients with EA [9,21,24], to best of our knowledge, there are only few reports of azygos continuation in infants with EA, all associated to left-isomerism [5,7,12].

Embryologically, the cardinal venous system with its anastomoses is the precursor of the IVC, the AV and the hemi-AV. Normally, the AV originates at the junction of the right ascending lumbar and subcostal veins, entering the thorax through the aortic hiatus. It ascends along the anterolateral surface of the thoracic vertebrae and arches ventrally just cephalad to the right main bronchus at T5-6, draining into the SVC or, more rarely, into the right brachiocephalic vein, right subclavian vein, intrapericardial SVC or right atrium [3,8]. Abnormal fusion between the hepatic and the prerenal segments of the IVC results in the infrahepatic hypoplasia or interruption of the IVC with azygos continuation and compensatory enlargement [19]. In that case, during EA repair it is important to do not perform a routine AV division in order to do not interfere with the inferior body venous drainage. Severe sequelae after AV division have been reported [4,13]. A similar surgical challenge exists during patent ductus arteriosus ligation and concomitant hemiazygos continuation on the left body side [22]. In light of this, it is reasonable the proposal of sparing the AV always during surgery to prevent early postoperative edema and leakage by maintaining physiological esophageal venous drainage [20].

The dilated azygos arch is a potential mimicker of aortic pathologies (dissection, aneurysm or rupture) [2] not only during thoracotomy, when the enlarged AV can mimic in caliber and course a right aortic arch, but also during imaging studies in more advanced ages in life. This anomaly may be isolated or associated with other anomalies, including abnormal cardiac situs and left-isomerism, bilateral SVC, atrial and ventricular septal defects, pulmonary stenosis, anomalous pulmonary venous return, pulmonary anomalies, like azygos/hemiazygos accessory lobe [3], or imperforate anus [6].

The incidence in patients with congenital heart disease undergoing cardiac catheterization is up to $1.3 \%$ [3]. During fetal echocardiography, the anomaly was encountered in $0.5 \%$, but reaches higher proportion (20.6\%) in case of associated omphalocele [14]. The exact reason for our high incidence is not known. The anomaly is in general underdiagnosed because asymptomatic unless it is not associated to laterality defects, arrhythmias, or venous thrombotic events. In the type III EA population, it can be misinterpreted as right aortic arch or its diagnosis can be missing or trivial and not reported because a vessel that looks bigger will however not be tied. However, little importance is given to asymptomatic vascular malformations, but represent a significant part of genetic diagnostic assessment. Asymptomatic pleural bounding azygos (hemiazygos) pulmonary lobe, as a discriminant for azygos continuation, might be not identifiable in newborns on anteroposterior or lateral X-ray due to normal neonatal thymus presence, like not the azygos continuation itself [16]. Color Doppler echocardiography is the most suitable non-invasive technique in detecting IVC interruption with azygos continuation [2,14], because the more sensitive $\mathrm{CT}$ is not recommended for routine vein or pulmonary screening exam. Furthermore, since the prenatal diagnosis of type III EA is quite difficult and based on indirect aspecific signs (polyhydramnios, altered gastric dimension), it should be examined whether the AV anomalies can represent an additional soft marker for gastrointestinal malformations.

Patients with IVC interruption have higher risk of thrombosis because of both impaired circulation and factor V deficiency [18]. There is still controversy whether an absent IVC is a developmental anomaly or the result of perinatal IVC thrombosis causing regression and disappearance of previously present IVC [10]. The IVC interruption is a hallmark for laterality defects. However, Mlczoch and Carvalho [14] debated that failure of IVC formation is not a situs abnormality in patients with omphalocele, despite frequently encountered in situs abnormalities. We support this theory, considering that our patients did not encompass at least three requested diagnostic categories for laterality defects [12]. Although low statistical power because of small study size, we think that the described association of rib anomalies, azygos continuation and EA arises from an early developmental disruption mechanism.

\section{Conclusions}

Despite of the associated rib number anomalies, the intraoperative possible confusion with aortic arch anomalies and the avoidance of surgical division, the azygos continuation of the IVC did not have a 
relevant clinical implication in the neonatal age. If during fetal US, the IVC is interrupted with azygos continuation to the SVC (right or leftsided), the diagnosis of isomerism should be considered and the possibility of an associated gastrointestinal abnormality should be investigated. The azygos continuation, unlike AV agenesis, has not been associated with wider esophageal gap or surgical complications. However, the foreknowledge of azygos continuation is important in case of thoracic surgery or interventional cardiac catheterization and should always be sought in the preoperative sonographic approach. Long-term follow-up may elucidate for associated thrombosis risk in patients with azygos continuation and EA.

\section{Funding source}

This research did not receive any specific grant from funding agencies in the public, commercial, or not-for-profit sectors.

\section{Financial disclosure}

The authors have indicated they have no financial relationships to this article to disclose.

\section{Conflict of interest}

The authors have indicated they have no potential conflicts of interest to disclose.

\section{References}

[1] D. Arbell, J. Golender, A. Khalaileh, E. Gross, Search for the azygos: a lesson learnt from a case with left superior vena cava, esophageal atresia and tracheo-esophageal fistula, Pediatr. Surg. Int. 25 (2009) 121-122.

[2] D.G. Blanchard, J.L. Sobel, J. Hope, A. Raisinghani, S. Keramati, A.N. DeMaria, Infrahepatic interruption of the inferior vena cava with azygos continuation: a potential mimicker of aortic pathology, J. Am. Soc. Echocardiogr. 11 (1998) $1078-1083$.

[3] T.C. Demos, H.V. Posniak, K.L. Pierce, M.C. Olson, M. Muscato, Venous anomalies of the thorax, AJR Am. J. Roentgenol. 182 (2004) 1139-1150.

[4] D.B. Effler, A.E. Greer, E.C. Sifers, Anomaly of the vena cava inferior; report of fatality after ligation, JAMA 146 (1951) 1321-1322.

[5] W.N. Evans, K. Kogut, R.J. Acherman, Preserving the azygos vein when repairing esophageal atresia and tracheoesophageal fistula accompanied by interrupted inferior vena cava, Pediatr. Surg. Int. 30 (2014) 345-347.

[6] M.L. Felicio, A.S. Martins, R.R. Andrade, M.A. Silva, Partial absence of the inferior vena cava associated with bowel malformation, Rev. Bras. Cir. Cardiovasc. 22
(2007) 362-364.

[7] F. Flor-de-Lima, A. Vilan, S. Pissarra, J. Ribeiro-Castro, J. Pereira, A.L. Neves, et al. Heterotaxy syndrome with esophageal atresia, J. Pediatr. 166 (2015) 1089.

[8] T.E. Geley, K.M. Unsinn, T.M. Auckenthaler, C.J. Fink, I. Gassner, Azygos continuation of the inferior vena cava: sonographic demonstration of the renal artery ventral to the azygos vein as a clue to diagnosis, AJR Am. J. Roentgenol. 172 (1999) 1659-1662.

[9] D.K. Gupta, M. Arora, M. Srinivas, Azygos vein anomaly: the best predictor of a long gap in esophageal atresia and tracheoesophageal fistula, Pediatr. Surg. Int. 17 (2001) 101-103.

[10] J. Iqbal, E. Nagaraju, Congenital absence of inferior vena cava and thrombosis: a case report, J. Med. Case Reports 2 (2008) 46.

[11] S. La Placa, M. Giuffrè, A. Gangemi, S. Di Noto, F. Matina, F. Nociforo, et al., Esophageal atresia in newborns: a wide spectrum from the isolated forms to a full VACTERL phenotype? Ital. J. Pediatr. 39 (2013) 45.

[12] A.E. Lin, S. Krikov, T. Riehle-Colarusso, J.L. Frías, J. Belmont, M. Anderka, et al., Laterality defects in the national birth defects prevention study (1998-2007): birth prevalence and descriptive epidemiology, Am. J. Med. Genet. A 164A (2014) $2581-2591$.

[13] A. Martín-Malagón, A. Bravo, I. Arteaga, L. Rodríguez, F. Estévez, A. Alarcó, Ivor Lewis esophagectomy in a patient with enlarged azygos vein: a lesson to learn, Ann. Thorac. Surg. 85 (2008) 326-328.

[14] E. Mlczoch, J.S. Carvalho, Interrupted inferior vena cava in fetuses with omphalocele. Case series of fetuses referred for fetal echocardiography and review of the literature, Early Hum. Dev. 91 (2015) 1-6.

[15] F. Morini, D.A. Cozzi, M. Ilari, A. Casati, F. Cozzi, Pattern of cardiovascular anomalies associated with esophageal atresia: support for a caudal pharyngeal arch neurocristopathy, Pediatr. Res. 50 (2001) 565-568.

[16] R.J. O'Reilly, J.H. Grollman, The lateral chest film as an unreliable indicator of azygos continuation of the inferior vena cava, Circulation 53 (1976) 891-895.

[17] R Core Team, R: A Language and Environment for Statistical Computing, R Foundation for Statistical Computing, Vienna, Austria, 2016http://www.R-project. org (accessed 11.11.16).

[18] M. Ruggeri, A. Tosetto, G. Castaman, F. Rodeghiero, Congenital absence of the inferior vena cava: a rare risk factor for idiopathic deep-vein thrombosis, Lancet 357 (2001) 441.

[19] A. Schneeweiss, L.C. Bleiden, V. Deutsch, A. Shem-Tov, H.N. Neufeld, Uninterrupted inferior vena cava with azygos continuation, Chest 80 (1981) 114-115.

[20] S. Sharma, S.K. Sinha, J.D. Rawat, A. Wakhlu, S.N. Kureel, R. Tandon, Azyos vein preservation in primary repair of esophageal atresia with tracheoesophageal fistula, Pediatr. Surg. Int. 23 (2007) 1215-1218.

[21] L. Spitz, N.M. Bax, A.G. Coran, Esophageal atresia with and without tracheoesophageal fistula, in: L. Spitz (Ed.), Operative Pediatric Surgery, sixth ed., Oxford University Press Inc., New York, 2006, pp. 109-151.

[22] Y. Tanoue, M. Masuda, M. Eto, R. Tominaga, Patent ductus arteriosus with hemiazygos communication to left superior vena cava, Ann. Thorac. Cardiovasc. Surg. 14 (2008) 256-257.

[23] T.R. Wells, B.H. Landing, W.R. Shankle, Syndromal association of common origin of the carotid arteries, Pediatr. Pathol. 13 (1993) 203-212.

[24] P.S. Yadav, N. Pant, R. Chadha, S.R. Choudhury, Oesophageal atresia and tracheoesophageal fistula with right pulmonary agenesis and duplication of the azygos vein, Arch. Dis. Child. 97 (2012) 513. 